\title{
AGLUTININAS ANTI-Leptospira spp EM SUÍNOS ABATIDOS EM MATADOURO-FRIGORÍFICO
}

\author{
AGGLUTININS ANTI-Leptospira spp IN PIGS SLAUGHTERED IN \\ SLAUGHTERHOUSE
}

\author{
E. B. XAVIER ${ }^{1 *}$, I. R. H. GATTO ${ }^{2}$, R. F. SANTOS ${ }^{2}$, D. A. PEREIRA ${ }^{3}$, K. A. NASCIMENTO ${ }^{3}$, \\ T. N. M. RAMOS ${ }^{4}$, L. A. MATHIAS ${ }^{5}$, L. G. OLIVEIRA ${ }^{6}$
}

\section{RESUMO}

A leptospirose assume grande importância econômica em criações de suínos, devido às grandes perdas e aos transtornos reprodutivos ocasionados pela doença. As sorovariedades mais envolvidas na infecção dos suínos são: Pomona, Icterohaemorrhagiae, Canicola, Gryppotyphosa, Bratislava e Copenhageni.. Assim, pretendeu-se com o presente trabalho determinar a frequência das sorovariedades presentes e a distribuição espacial da Leptospira spp. em suínos em determinadas mesorregiões de alguns estados brasileiros. Foram colhidas 549 amostras de sangue de suínos em matadouros-frigoríficos das mesorregiões: Norte Pioneiro Paranaense (PR), Centro-Sul Paranaense (PR), Oeste Catarinense (SC) microrregiões Chapecó, Joaçaba e Concórdia -, Sudoeste de Mato Grosso do Sul (MS), Ribeirão Preto (SP), Sul Goiano (GO). As amostras de soro sanguíneo foram submetidas ao teste de soroaglutinação microscópica (SAM), para o diagnóstico da leptospirose, utilizando 24 sorovares de leptospiras (patogênicas e saprófitas). Foram observados 217 (39,5\%) suínos sororreagentes a pelo menos uma das 24 sorovariedades testadas, com título igual ou superior a 100. Os sorovares predominantes foram Icterohaemorrhagiae nos estados de Goiás (44,8\% - Sul ), Mato Grosso do Sul (18,5\% - Sudoeste) e Paraná (10,1\% -Norte Pioneiro e 55,2\%-Centro Sul). Em Santa Catarina houve predominância de Icterohaemorrhagiae (40,5\% - Chapecó; 18,2\% - Joaçaba) e Cynopteri (20\%- Joaçaba e 11,9\% Concórdia), e em São Paulo, de Cynopteri (34,5\%- Ribeirão Preto). Os títulos de anticorpos variaram de 100 a 400. Por apresentarem títulos, pode-se inferir que em algum momento da criação esses animais entraram em contato com uma fonte de infecção ou meio de transmissão. Além disso, pode-se associar o resultado encontrado ao grau de tecnificação da granja, ao manejo e ao ambiente, sendo de suma importância medidas de biosseguridade do plantel. Deve-se atentar, também, ao risco que esses animais proporcionam aos magarefes e tratadores, por se tratar de uma zoonose de grande impacto na saúde pública.

PALAVRAS-CHAVE: LEPTOPIROSE. SOROAGLUTINAÇÃO MICROSCÓPICA. SUINOCULTURA.

ÁREA TEMÁTICA: Doenças infecciosas. 